\title{
ESTUDO DA ADIÇÃO DE RESÍDUO DE VIDRO EM CERÂMICA VERMELHA ESTRUTURAL ${ }^{1}$
}

\author{
STUDY OF ADDITION OF GLASS WASTE IN STRUCTURAL RED CERAMIC
}

\author{
Isabela Patrícia da Silva Galves², Dionata Alberto Budel ${ }^{3}$, Fabrício Kuhn da Silva ${ }^{4}$, \\ Gabriel Ungaretti Monson ${ }^{5}$ e Luiz Fernando Rodrigues Junior ${ }^{6}$
}

\section{RESUMO}

Apesar de o vidro ser um material passível de reciclagem, esse processo, muitas vezes, não é realizado devido às dificuldades de logística e pela necessidade de se reciclar separadamente os vidros de cores diferentes. Esses aspectos acarretam problemas ambientais de grande volume e de difícil resolução. Por outro lado, o uso de cerâmicas vermelhas estruturais apresenta diversos problemas técnicos relacionados a propriedades mecânicas e à absorção de água. Diante disso, com este trabalho, visou-se estudar a adição de resíduo de vidro em massa cerâmica usada na produção de tijolos vermelhos. Para tal, as amostras de vidro e argila foram secas, moídas e misturadas nas proporções de 0,20 e $50 \%$ em massa de vidro na argila. Para caracterizar as amostras quanto à estrutura química, foi utilizada a difração de raios-X e, para avaliar as propriedades dos produtos, foi utilizado o ensaio de flexão a quatro pontas. Também foi realizado o ensaio de absorção de água para avaliar o efeito do vidro nos poros da massa cerâmica. Os resultados demonstraram a presença de fases características de argilas usadas em cerâmicas vermelhas estruturais, e os resultados de absorção de água mostram uma redução de 11,5\% para 7,8\% entre as amostras sem adição e com adição de 50\% de vidro. Quanto à resistência mecânica, houve um aumento da tensão média de ruptura de 2,8 MPa (amostra sem vidro) para 14,4 MPa (amostra com 50\% de vidro). Dessa forma, pode-se considerar adequada a adição de vidro na massa cerâmica para produtos estruturais.

Palavras-chave: absorção de água, argila, tijolo.

\section{ABSTRACT}

Although glass can be recycled, its process is often not carried out due to logistic difficulties and the need to separately recycle glass of distinct colors. These problems entail high-volume and difficult-to-resolve environmental hazards. On the other hand, the use of structural red ceramics presents several technical problems related to mechanical properties and water absorption. In light of this scenario, this work aimed to study the addition of glass residue in a ceramic mass used in the production of red bricks. For this purpose, the glass and clay samples were dried, ground and mixed in proportions of 0,20 and 50\% by mass of glass in clay. X-ray diffraction was used to characterize the samples as to their chemical structure and to evaluate the properties of the products, the 4-point bending test was used. The water absorption test was also carried out to evaluate the effect of glass on the pores of the ceramic mass. The results have shown the presence of characteristic phases from clay used in structural red ceramics and the water absorption results has shown a reduction from $11.5 \%$ to $7.8 \%$, between samples without addition and with addition of $50 \%$ of glass. Regarding mechanical strength, there was an increase in average tensile strength from $2.8 \mathrm{MPa}$ (sample without glass) to $14.4 \mathrm{MPa}$ (sample with $50 \%$ glass). Therefore, the addition of glass to the ceramic mass for structural products can be considered adequate.

Keywords: water absorption, brick, clay.

1 Trabalho realizado na disciplina Materiais Cerâmicos I

2 Acadêmica do Curso de Engenharia de Materiais - Universidade Franciscana - UFN. E-mail: isabela.galves@ufn.edu.br 3 Acadêmico do Curso de Engenharia de Materiais - Universidade Franciscana - UFN. E-mail: dionata.budel@ufn.edu.br 4 Acadêmico do Curso de Engenharia de Materiais - Universidade Franciscana - UFN. E-mail: fabricio.kuhn@ufn.edu.br 5 Acadêmico do Curso de Engenharia de Materiais - Universidade Franciscana - UFN. E-mail: gabriel.umonson@ufn.edu.br 6 Orientador - Universidade Franciscana - UFN. E-mail: luiz.fernando@ufn.edu.br 


\section{INTRODUÇÃO}

A destinação inadequada dos resíduos pelo ser humano e pelas empresas nos dias de hoje é algo recorrente. Os resíduos fazem parte do ciclo de produção, no qual, após a utilização pelo consumidor final, são descartados no meio ambiente. Por consequência disso, tornam-se materiais altamente poluentes e, com o vidro, não é diferente. Todos os dias, milhares de garrafas, vasilhames diversos, vidros de construção civil, entre outros, são descartados na natureza.

Segundo dados Revista do Meio Ambiente Industrial (2019), o Brasil produz cerca de 980 mil toneladas de embalagens de vidro por ano, e 45\% dessa matéria prima é oriunda de cacos de reciclagem, sendo que, em 2011, o Brasil reciclou cerca de 47\% de embalagens de vidro, totalizando 470 mil ton./ano. Destes, $40 \%$ são de indústria de envase, $40 \%$ do mercado difuso, $10 \%$ do "canal frio" (restaurantes, bares etc.) e 10\% do refugo das indústrias.

O índice de reciclagem de vidro na Alemanha, em 2009, era em torno de 81\%, já em 2010, aumentou para $87 \%$, o que corresponde a 2,6 toneladas. A partir desses dados, pode-se observar que houve um aumento no índice de reciclagem, se tratando de um país desenvolvido. O índice de reciclagem dos Estados Unidos gera em torno de 40\%, número inferior ao do Brasil. Já a Suíça recicla em torno de 95\% do vidro, número bastante superior ao dos Estados Unidos. Apesar do número elevado na Suíça, em geral, o resíduo gerado pelos vidros é pouco aproveitado pela maioria dos países (REVISTA DO MEIO AMBIENTE INDUSTRIAL, 2019).

Os produtos de cerâmica vermelha fazem parte de um grupo com alto potencial para a adição de resíduos (MENEZES; NEVES; FERREIRA, 2002). Uma das grandes razões para isso é que envolvem um grande volume de produção e, consequentemente, um grande volume de matéria prima, sua capacidade de encapsulamento de materiais inertes (GODINHO et al. 2005). De acordo com Nandi et al. (2014), quanto maior for o teor de umidade presente nas amostras, maior será a sua retração linear. Essa característica está relacionada à quantidade utilizada de água durante a fabricação dos corpos de prova e à evaporação durante a secagem. Assim, quanto mais vidro for adicionado à mistura, menor será o teor de umidade presente na amostra em questão. Outro fator a ser observado é em relação às propriedades mecânicas dos corpos de provas com adição do vidro e pós queima. Com relação a esse aspecto, Zaccaron et al. (2016) referem que "o aumento da temperatura de queima acarreta uma melhor resistência mecânica média das amostras, pois o vidro incorporado à massa cerâmica amolece após determinada temperatura, tornando a estrutura mais compacta e assim mais resistente".

Com este estudo, objetiva-se realizar a avaliação da inserção de resíduo de vidro em massa cerâmica vermelha estrutural, avaliando propriedades físicas, químicas e mecânicas dos produtos obtidos de forma a verificar as variações na absorção de água, resistência mecânica e fases cristalinas presentes. 


\section{MATERIAIS E MÉTODOS}

\section{PREPARO DAS AMOSTRAS}

Para compreender melhor o efeito do vidro na composição de uma massa cerâmica vermelha estrutural, optou-se por usar a argila utilizada na confecção de tijolos de uma olaria da cidade de Santa Maria. O vidro foi obtido de garrafas do tipo âmbar, que foram secas e lavadas antes de serem utilizadas. Para a mistura das massas usadas na confecção dos corpos de prova, tanto a argila como o vidro foram moídos em moinho de bolas Servitech, modelo CT-241 e, posteriormente, peneiradas em peneiras \#60 mesh. A produção dos corpos de prova foi feita em uma prensa uniaxial com pressão de $45 \mathrm{MPa}$, por $30 \mathrm{~s}$, sendo utilizado um molde com $12 \mathrm{~mm}$ de largura e $83 \mathrm{~mm}$ de comprimento, $20 \mathrm{~g}$ de material e adição de $10 \%$ de água à massa seca. Os corpos de prova foram secos ao ar livre por 24 horas e depois sinterizados em forno mufla na temperatura de $950{ }^{\circ} \mathrm{C}$, com tempo de patamar de 60 minutos rampa de $10{ }^{\circ} \mathrm{C} / \mathrm{min}$. Para estudar a influência do vidro na massa cerâmica, foram realizadas três misturas em uma relação mássica de: $0 \%$ de vidro (amostra 100/0); 20\% de vidro (amostra 80/20) e 50\% de vidro (amostra 50/50). Na figura 1, tem-se o fluxograma com a representação dos processos evolvidos na produção das amostras.

Figura 1 - Fluxograma do processo.

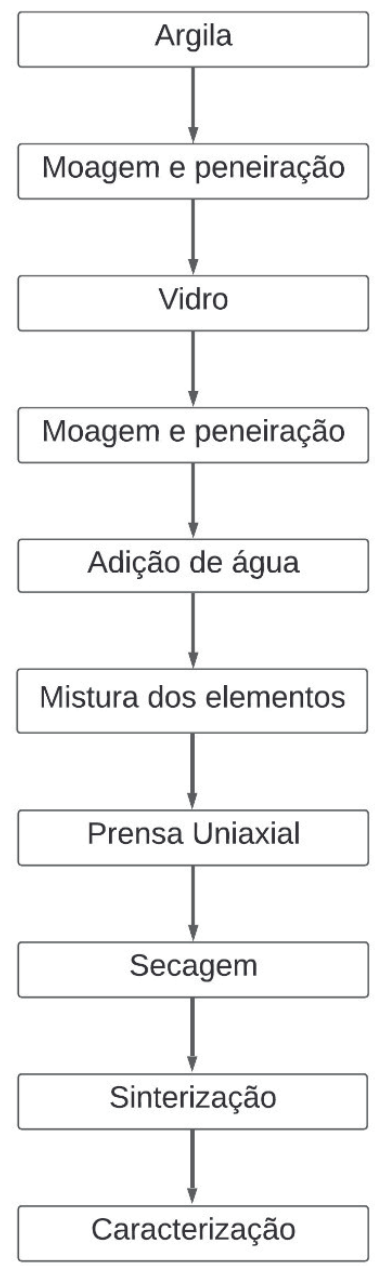

Fonte: Construção do Autor. 
CARACTERIZAÇÃO

\section{Difração de raios-X}

Para a análise de difração de raios-X, foi utilizado o Difratômetro Bruker, modelo D2 Advance Bruker, com tubo de cobre (radiação $\mathrm{K} \alpha=1,5418 \AA$ ) ). A tensão e a corrente utilizadas no tubo foram $30 \mathrm{kV}$ e $10 \mathrm{~mA}$, respectivamente. A velocidade de varredura do goniômetro foi de $0,02 \%$, sendo o intervalo de varredura de $10^{\circ}$ a $70^{\circ}$.

\section{Determinação do índice de absorção de água}

Para o ensaio de absorção de água, foram usadas seis amostras de cada mistura. As peças foram colocadas em um recipiente com água, que foi levado, progressivamente, em fervura. Após atingir a temperatura de fervura, as amostras ficaram imersas por um período de 2 horas, sendo retiradas, secas e resfriadas em temperatura ambiente por 12 horas. Para realizar o cálculo de AA, foi utilizada a eq. (1), fazendo uso de uma balança analítica Bel Engineering modelo Mark K 12001.

$$
A A(\%)=\left(\frac{M u M s}{M s}\right) \times 100
$$

Em que:

Mu é a massa úmida e

Ms é a massa seca dos corpos de prova.

\section{Ensaio de flexão a quatro pontos}

O ensaio de flexão de quatro pontos foi realizado em uma máquina de ensaios universal EMIC, modelo DL10000. Para cada variação percentual entre vidro e argila, foram realizados ensaios com seis corpos de prova para cada uma dessas misturas. Conforme descrito por Duarte (2000), o ensaio de flexão a quatro pontos tem a finalidade de avaliar o comportamento mecânico em materiais cerâmicos e pode ser calculado a partir da eq. (2).

$$
\sigma_{4 p}=\frac{3 P d}{B h^{2}}
$$

Em que:

P é a carga aplicada,

d é a distância entre os cutelos inferior e superior de um mesmo lado,

b é a largura e

$\mathrm{h}$ a altura do corpo. 


\section{RESULTADOS E DISCUSSÃO}

Na figura 2, é apresentado o difratograma de raios-X da amostra de argila como recebida. $\mathrm{O}$ resultado demonstra a prevalência das fases Quartzo $\left(\mathrm{SiO}_{2}\right)$, Hematita $\left(\mathrm{Fe}_{2} \mathrm{O}_{3}\right)$, Ilita/Mica $\left(\left(\mathrm{K}_{3} \mathrm{H}_{3} \mathrm{O}\right)\right.$ $\left.(\mathrm{Al}, \mathrm{Mg}, \mathrm{Fe})_{2}(\mathrm{Si}, \mathrm{Al})_{4} \mathrm{O}_{10}\left[(\mathrm{OH})_{2},\left(\mathrm{H}_{2} \mathrm{O}\right)\right]\right)$ e Caulinita $\left(\mathrm{Al}_{2} \mathrm{O}_{3} \cdot 2 \mathrm{SiO}_{2} \cdot 2 \mathrm{H}_{2} \mathrm{O}\right)$. Esses resultados estão em acordo com o observado por outros autores para a composição presente em argilas utilizadas para a produção de cerâmicas vermelhas estruturais (BRUXEL et al., 2012; MACEDO et al., 2008; RODRIGUES et al., 2019).

Após a sinterização dos corpos de prova, foram realizados ensaios de difração de raios-X em cada uma das variações das misturas entre vidro e argila (Figura 3). Como se pode observar, a fase quartzo se manteve estável durante o processo de sinterização a temperatura de $950{ }^{\circ} \mathrm{C}$, diferentemente da fase caulinita que, possivelmente, sofreu decomposição durante a sinterização (RODRIGUES et al., 2019). A fase hematita foi observada após a sinterização, e sua presença é característica desse tipo de argila com coloração vermelha após a sinterização (RODRIGUES et al., 2019). Comparando os difratogramas com presença de vidro na mistura, percebe-se a presença da fase cristobalita $\left(\mathrm{SiO}_{2}\right)$ na amostra 80/20 e um pico ainda mais intenso na amostra 50/50. Esse resultado demonstra a transformação do vidro amorfo em uma fase cristalina do óxido de silício. A diminuição do pico referente à hematita nas amostras contendo vidro (80/20 e 50/50) pode estar relacionada à menor quantidade de argila na mistura e à capacidade de detecção da difração de raios-X.

Figura 2 - Difratograma de raios- $\mathrm{X}$ da amostra de argila sem ter sido sinterizada.

(Quartzo - JCPDS:46-1045; Caulinita - JCPDS:14-0164; Hematita - JCPDS: 33-0664 \& Ilita/Mica - JCPDS: 831808).

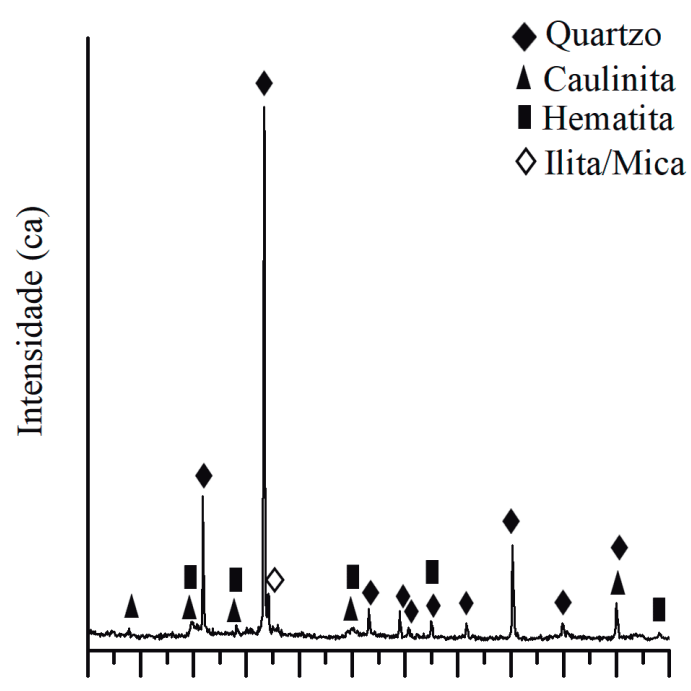

101520253035404550556065

$2 \theta$

Fonte: Construção do Autor 
Figura 3 - Difratograma de raios-X das amostras após o processo de sinterização.

(Quartzo - JCPDS:46-1045; Cristobalita - JCPDS: 82-0512 \& Hematita - JCPDS: 33-0664).

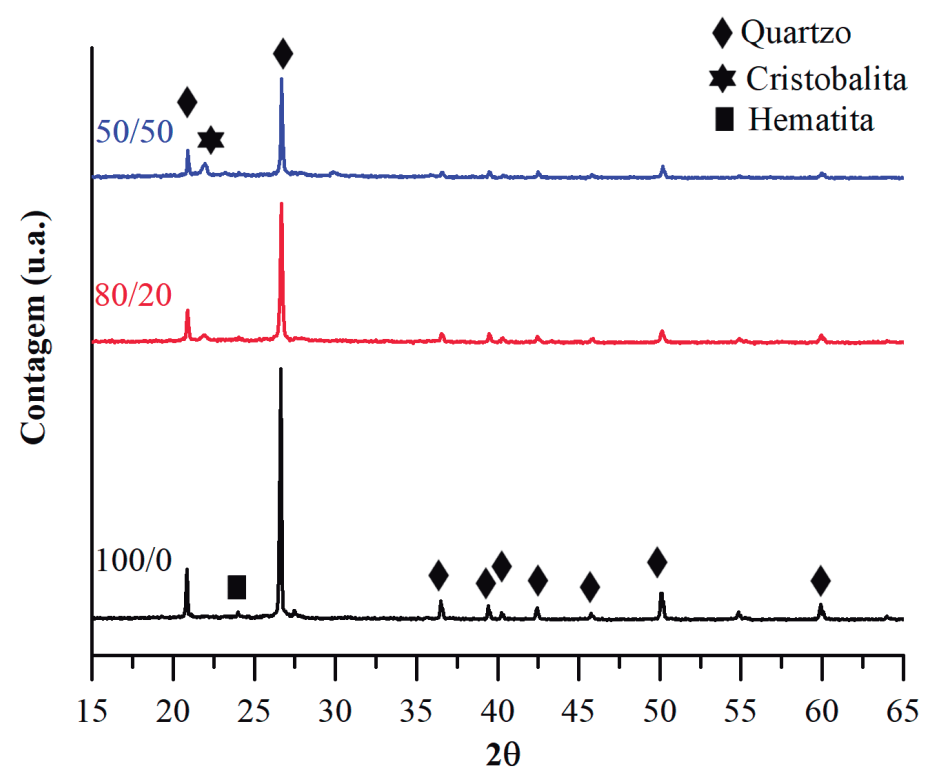

Fonte: Construção do Autor

No teste de absorção de água (Figura 4), pode-se observar que, com a adição de 50\% de vidro à massa cerâmica, houve uma grande redução da capacidade das amostras em absorver água. Contudo esse comportamento não foi observado para a amostra com adição de $20 \%$ de resíduo de vidro, sendo o seu valor médio de absorção de água levemente superior ao da amostra sem vidro (11,5\% e 12,0\% para as amostras 100/0 e 80/20, respectivamente), entretanto essa diferença não pode ser considerada estatisticamente diferente $(\mathrm{p}=0,87)$. Quando comparado o valor de absorção de água da amostra 50/50 (7,8\%) com o valor das demais, percebe-se que houve uma diferença estatística significativa, com valor de $\mathrm{p}<0,05$ para as amostras sem vidro e com $20 \%$ de vidro. Esse comportamento de redução da absorção de água está relacionado ao efeito fundente do vidro na massa cerâmica e foi observado por Godinho et al. (2004).

Figura 4 - Gráfico para os valores de absorção de água das amostras com diferentes adições de vidro a massa cerâmica de argila. $(*)$ diferença significativa com $\mathrm{p}<0,05$. (**) não existe diferença significativa entre as amostras.

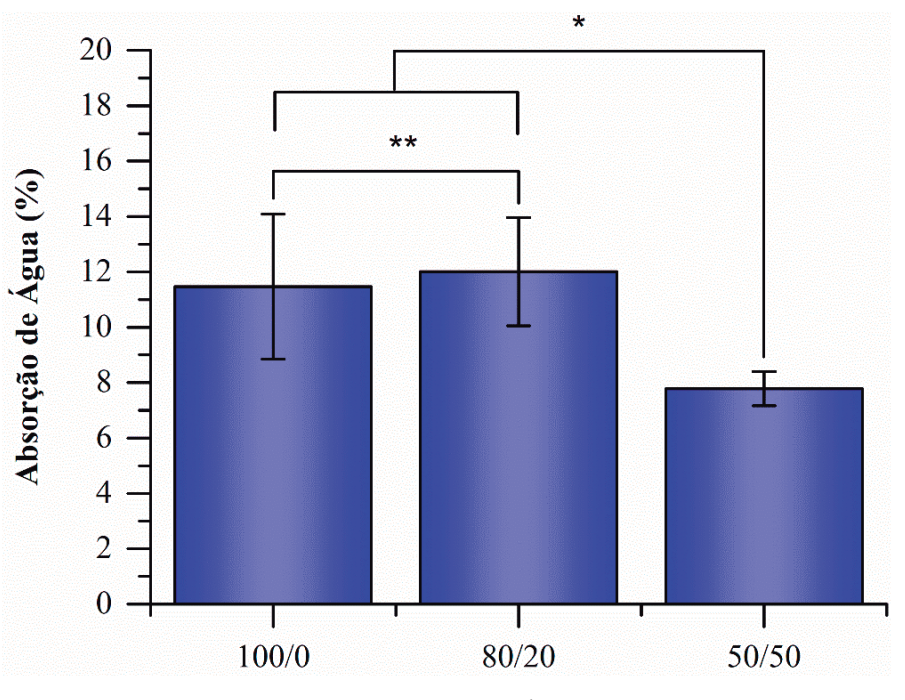

Fonte: construção do autor. 
Na Figura 3, são apresentados os dados referentes ao ensaio de flexão quatro pontos das amostras. O valor de tensão a flexão quatro pontos medido para a amostra com adição de $50 \%$ de vidro é cerca de cinco vezes maior em comparação com amostras sem adição de vido (2,8 Mpa e 14,4 Mpa, respectivamente) e apresenta diferença estatística com valor de $\mathrm{p}<0,05$. Quando comparado o valor de tensão média para a amostra com $20 \%$ de vidro e a amostra sem vidro, pode-se perceber um aumento de aproximadamente $2 \mathrm{MPa}$, contudo essa diferença não pode ser considerada estatisticamente diferente $(\mathrm{p}=0,15)$. As amostras com adição de vidro (50/50 e 80/20) também apresentaram diferença estatística entre si, com valor de $\mathrm{p}<0,05$. Esses resultados demonstram que a quantidade de vidro presente na massa cerâmica influencia drasticamente nas propriedades mecânicas (LICURGO; VIEIRA, 2018). Essa grande influência está relacionada aos elementos fundentes presentes no vidro que auxiliam no processo de sinterização, reduzindo a quantidade de poros do material (SCHARNBERG et al.; 2019). Esses resultados estão em acordo com o observado pelo ensaio de absorção de água, o qual apresenta uma relação direta com a porosidade aparente do material (DUTRA; DE ARAÚJO PONTES, 2002; SCHARNBERG, et al., 2019), e com a formação de cristobalita observada pelo ensaio de DRX.

Figura 5 - Gráfico de tensão a flexão 4 pontas para as amostras com diferentes adições de vidro a massa cerâmica de argila. $(*)$ diferença significativa com $\mathrm{p}<0,05$. $(* *)$ não existe diferença significativa entre as amostras.

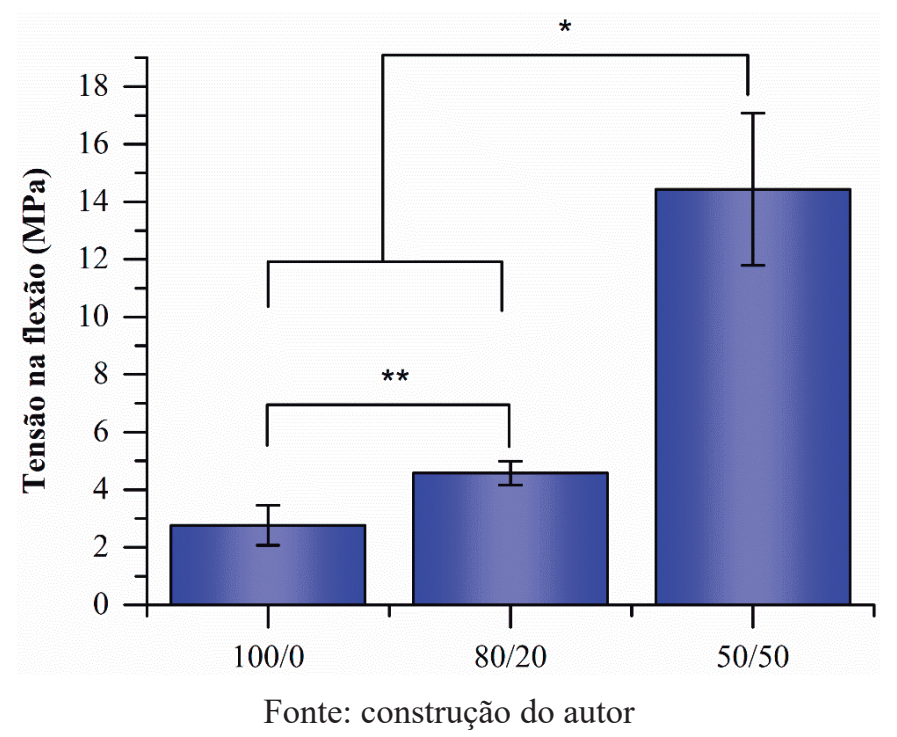

\section{CONCLUSÃO}

A partir dos resultados para os testes físicos, químicos e mecânicos, é possível afirmar que a adição de vidro à massa de argila possibilitou a formação de produtos cerâmicos sinterizados. Esses produtos apresentaram redução da capacidade de absorção de água e um aumento da resistência mecânica a flexão quatro pontos com a adição de vidro à massa de argila. Porém os resultados demonstraram que existe a necessidade da adição de quantidades superiores a $20 \%$ de vidro à massa da argila para que sejam obtidas mudanças significativas nas propriedades físicas e mecânicas. Além disso, foi possível observar pelo DRX a formação da fase cristobalita na amostra com adição de vidro, o que 
demonstra a alteração da estrutura amorfa para uma fase cristalina. Com base no observado, pode-se inferir que há possibilidade de se ter um ganho em propriedades pela adição do vidro à massa de argila vermelha, além da aplicação de um resíduo em um novo produto e a redução de matéria-prima virgem pela substituição da argila pelo vidro.

\section{REFERÊNCIAS}

BRUXEL, F. R. et al. Estudo da adição de resíduo (lodo) de gemas na massa cerâmica vermelha. Cerâmica, v. 58, n. 346, p. 211-215, 2012. Disponível em: https://bit.ly/3EtxEp3. Acesso em: 17 set. 2021.

DUARTE, E. A. DE CARVALHO, E. T. V. Laboratório de Materiais Avançados Universidade Estadual do Norte Fluminense, Av. Alberto Lamego, 2000 - Campos - RJ - 28015-620.

DUTRA, R. P. S.; DE ARAÚJO PONTES, L. R. Obtenção e análise de cerâmicas porosas com a incorporação de produtos orgânicos ao corpo cerâmico (Obtaining and analysis of porous ceramic with the incorporation of organic. Cerâmica, v. 48, n. 308, p. 223-230, 2002.

GODINHO, K. O. et al. Incorporação de resíduo de vidro em cerâmica vermelha. In: CONGRESSO BRASILEIRO DE CERÂMICA, 48, 2004, Curitiba. Anais [...]. Curitiba: IPEN, 2004. p. 1-10. Disponível em: https://bit.ly/3z3lVfJ. Acesso em: 12 ago. 2020.

GODINHO, K. O. et al. Obtenção e avaliação de propriedades tecnológicas de corpos cerâmicos à base de argila e vidros reciclados, Cerâmica, São Paulo, v. 51, n. 320, out./dez., 2005.

LICURGO, J. S. C.; VIEIRA, C. M. F. Aproveitamento de resíduo da etapa de lapidação de vidro em cerâmica vermelha. In: CONGRESSO ANUAL DA ABM, 70, 2018, São Paulo. Anais [...]. São Paulo: Blucher, 2018. p. 753-761. Disponível em: https://bit.ly/3qrxARK. Acesso em: 17 jun. 2021.

MACEDO, R. S. et al. Estudo de argilas usadas em cerâmica vermelha. Cerâmica, v. 54, n. 332, p. 411-417, 2008. Disponível em: https://bit.ly/3et9ctt. Acesso em: 25 set. 2021.

MENEZES, R. R.; NEVES, G. A.; FERREIRA, H. C. Revista Brasileira de Engenharia Agrícola e Ambiental, v. 6, n. 2, p. 303-313, 2002. 
NANDI, V. de S. et al. Adição de vidro reciclado de lâmpadas na fabricação de cerâmica vermelha.

Cerâmica Industrial, v. 19, n. 5, p. 29-32, 2014. Disponível em: https://bit.ly/3mATDo4. Acesso em: 12 out. 2021.

REVISTA MEIO AMBIENTE INDUSTRIAL. Nova tecnologia da TOMRA recupera mais vidro para reciclagem. 2019. Disponível em: https://bit.ly/3EzsXdr. Acesso em: 13 dez. 2020.

RODRIGUES, L. R. et al. Resíduo do processo Kraft (dregs) como matéria-prima alternativa para cerâmica vermelha. Cerâmica, v. 65, n. 373, p. 162-169, 2019. Disponível em: https://bit.ly/3mATKA0. Acesso em: 17 jun. 2021.

SCHARNBERG, A. R. A. et al. Avaliação da adição de resíduos de vidro sodo-cálcico e erva-mate em matriz cerâmica. Cerâmica, v. 65, n. 373, p. 63-69, 2019. Disponível em: https://bit.ly/3qrurRR. Acesso em: 2 nov. 2021.

ZACCARON, A. et al. Utilização de vidro de garrafas para redução da absorção de água em produtos de cerâmica vermelha, Cerâmica Industrial, v. 21, n. 5-6, p. 35-39, 2016. Disponível em: https:// ceramicaindustrial.org.br/. Acesso em: 13 dez. 2020. 